\title{
Formação de Dirigentes no Serviço Público Federal
}

Bob L. Wynia

Da Universidade de Oregon, EUA

Tradução de Marcos Henrique C. Côrtes

Fonte: Public Administration Review, Jul./Ago. 1972

A formação de dirigentes nunca foi questão prioritária dentro de nossa estrutura administrativa. Embora tenhamos sempre reconhecido a necessidade de se contar com funcionários de qualidade e bem treinados, na sua maioria esses elementos são, depois de nomeados, entregues à sua própria sorte no que se refere a aprimorar sua capacidade, aprender novas técnicas ou adquirir novos conhecimentos. Este artigo tenta ressaltar algumas das deficiências do sistema atual de "treinamento" de dirigentes no âmbito federal e busca o desenvolvimento de um sistema novo e melhorado de "formação e treinamento". Com a aprovação da "Lei sobre Pessoal e Treinamento Intergovernamental", este artigo adquire maior significação. Ao tomar a iniciativa desse importantíssimo projeto, a "Civil Service Commission" (Comissão do Serviço Público) e o "Office of Management and Budget"' (Escritório de Administração e Orçamento) têm a oportunidade de instituir pesquisas muito necessárias e de desenvolver um sistema amplo de formação e treinamento.

Há vários meses um funcionário do Departamento de Defesa decidiu manifestar seu individualismo, sua consciência e o que considerou seu direito Q dever como cidadão, informando o Público americano sobre gastos excessivos em contratos governamentais. Foi demitido. 1

Em maio de 1967, um funcionário civil de um órgão naval queixou-se ao

1. Barbara Newman, "The Cost of Courage: The Pentagon's Loneliest Man". The Washington Monthly, Vol. I, N. ${ }^{\circ}$ 67-69.
Secretário da Marinha sobre formas de contratação e de promoção em sua repartição. Foi demitido. 2

Em junho de 1968 um funcionário, professor de escola pública, escreveu uma carta ao diretor de um jornal de sua cidade criticando a junta diretora da escola por seus métodos de alocação de recursos orçamentários. Foi demitido. 3

\footnotetext{
2. Vide a questăo na Suprema Corte "Swaaley versus United States", 5-67.

3. Vide a questăo na Supremá Corte "Pickering versis Board of Education", 6-3-68.
}

R. Serv. Públ., Brasília, 108 (1): jan/abr. 1973 
Há muitissimos outros casos que poderiam ser citados para demonstrar a tese de que o individualismo não é muito bem recebido no serviço público.

Essa perda de individualismo produz um efeito a longo prazo que agora se está fazendo sentir em todos os órgãos da administração federal. A criatividade parece ter chegado a um nível baixíssimo nunca atingido antes. 0 medo de represálias parece estar num ponto mais alto do que nunca. A suspeita em relação ao individuo se espalha por todas as carreiras do serviço público federal, não sobre suas qualificaçōes para "fazer o trabalho" mas sobre sua "lealdade" para com a organização a que pertence, o partido politico e a filosofia democrática. 4

O chamado sonho americano se está rapidamente transformando num mito. Em eras passadas esse sonho tradicional se centrava no individualismo, na independência, na liberdade de pensamento e de ação e na capacidade inovadora. 5

Essa noção de governo se coadunava com um sistema econômico que tentava corporificar o sonho americano. Ela procurava tornar possivel para cada cidadäo

4. Albert O. "Hirschman, "The Culture of Bureaucracy: Exit, Voice and Loyalty". The pg. 24.

5. Vide, por exemplo, o exame da vocaçăo individualista norte-americana feito por Slater no livro "The Pursuit of Loneliness" (Boston: Beacon Press, 1970), pg. 25; e também o livro altamente controvertido "The Greening of America" (New York: Random House, 1970), por Charles Reich, especialmente o capitulo sobre "A Personalidade Perdida", pg. 129.

R. Serv. Públ., Brasília, 108 (1): jan/abr. 1973 americano conquistar sua independência econômica pessoal, a propriedade de suas terras e seu lar, e uma oportunidade de definir e fazer o tipo de trabalho que escolhesse. Dentro desse esquema havia, evidentemente, possibilidades para alguns se tornarem ricos, alguns continuarem ricos e outros para continuarem ou ficarem pobres. Porém isso era considerado necessário para o objetivo global de independência pessoal. A fronteira estava aberta; as oportunidades podiam ser encontradas em toda parte; não havia leis que restringissem a liberdade de movimento; havia uma liberdade virtualmente ilimitada para definir a "busca da felicidade" de qualquer forma que parecesse satisfatória à pessoa interessada. 6

Hoje em dia as possibilidades de um homem começar sua própria firma, comprar uma pequena fazenda no oeste, etc., só se concretizam por empatia para os que pertencem à grande maioria dos americanos de classe média. Começa-se a considerar a herança como praticamente a única forma de se chegar a esse tipo de independência. O gigantismo do governo e da indústria privada nos roubaram muito de nossa independência. A maioria das pessoas é hole de empregados, sobretudo de grandes organizações. Eric Hoffer se delicia em mostrar como esse gigantismo é um produto do capitalismo autoritário e esse autoritarismo conduz a menos individualismo, o que, segundo ele, é benéfico na medida em

6. Charles A. Reich, "The Greening of Ame" rica", op. cit., pg. 31 . 
que elimina a responsabilidade individual, que é o que a maioria das pessoas realmente deseja. Tullock, em seu livro "The Politics of Bureaucracy" (A Politica da Burocracia), diz que "se temos de ter gigantismo burocrático, vamos, pelo menos, abrir os olhos para seu funcionamento interno. O homem não deixa simplesmente de existir por estar submerso em uma hierarquia administrativa. Ele continua sendo um individuo, com motivações, impulsos e desejos individuais." 7

O gigantismo veio para ficar e para aumentar ainda mais. Com 0 atual crescimento de conglomerados, empresas agricolas, Departamentos como o de Saúde, Educação e Bem-Estar, e até mesmo órgãos de governos estaduais e municipais, veio também a dominação organizacional do individuo, sua familia, sua carreira e seu estilo de vida. As decisões de outros dominam a vida do funcionário subalterno, do chefe de nivel médio e até do chefe de escalão superior. Atualmente, quantos funcionários procuram vestir a rouPa certa, ter o modelo de carro certo, viver no bairro certo, freqüentar as reuniōes sociais certas e redigir os expedientes certos da forma certa? E o que é certo? Parece muito claro que os administradores freqüentemente ditam o que é certo, tal como o fazem os vizinhos, amigos e entidades. 0 comportamento tende a ser orientado Para o bem da organização, ao invés de obedecer primeiro a considerações de ordem pessoal ou de familia. O funcionário é, na verdade, um prisio-

7. Gordon Tullock, "The Politics of Bureaucracy" (Washington, D.C.: Public Affairs Press, 1965), pg. 2. neiro da grande organização, da entidade, da repartição. As responsabilidades por sua vida, sua carreira, seu estilo de vida foram entregues às pessoas acima dele.

No serviço público, especialmente nas carreiras da administraçăo federal, o individualismo é olhado via de regra como, no mínimo, ameaçador, revolucionário no sentido negativo do termo e antiorganização. Os jovens parecem excessivamente radicais ao formularem reivindicações baseadas nos direitos humanos, tais como igualdade de tratamento, participação no processo decisório, e comissões imparciais para examinarem discórdias trabalhistas. Os funcionários mais velhos e entrincheirados em suas posições encaram o funcionário que faz perguntas, levanta dúvidas e sugere novas alternativas como um "criador de caso", uma pessoa interessada apenas em "destruir o sistema". E a verdade é que os funcionários mais velhos e entrincheirados, que servem em órgãos como a "Civil Service Commission" (CSC), a "Social Security Administration" (Administração de Segurança Social), o "Bureau of Indian Affairs" (Escritório de Assuntos Indigenas) e outros, estão profundamente preocupados com que esses jovens dissidentes possam destruir suas "panelinhas", que os protegeram e promoveram a posiçōes de poder e prestígio.

Deixamos de cuidar dos problemas de modificação dos estilos de organização, de relações humanas dentro da organização, de necessidades individuais etc. A carreira de um individuo, seus estilos de vida, suas preo-

R. Serv. Públ., Brasilia, 108 (1): jan/abr. 1973 
cupações. pessoais foram relegados a segundo plano pelos projetos, eficiência e produção da organização. 8 Contudo, como Dylan diz de forma tão bela "the times are a'changin"" ("os tempos se estão a mudar"). A questão é se podemos mudar. Pode uma burocracia, encrustada em um século de tradição e uma geração completa 'do que Anthony Downs chama "conservantistas", enfrentar as novas exigências que lhe são opostas? Para atender a essas exigências será necessária uma burocracia re-treinada - re-treinada em novos estilos de administração, novas estruturas de organização, novas técnicas de tomada de decisão.

\section{Preparação para o Amanhã}

É tendo em mente essas exigências, a perda do individualismo, uma aparente falta de criatividade e a calcificação do burocrata de carreira, que fazemos um breve exame de como estamos atualmente tentando "treinar" ou "re-treinar" ou "formar" dirigentes no setor governamental e o que é necessário para preparar os dirigentes do serviço público para o amanhã.

Todo ano milhões de dólares e miIhares de homens-hora são despendidos no que o governo federal denomina programas de "treinamento" ou "formação de dirigentes". Os programas variam de seminários e reuniōes curtos, de um ou dois dias, a programas de treinamento de um ano completo em universidades. Que se ganhou com o gasto de vários bilhões de dólares nesses poucos anos? Parece que

\footnotetext{
8. John Gardner, "Self-Renewal" (New York Harper and Row, 1963), pgs. 92-93.
}

R. Serv. Públ., Brasilia, 108 (1): jan/abr. 1973 ninguém sabe ao certo. Alguns especulam sobre "melhor administração" e "dirigentes mais eficientes", porém jamais se fez uma avaliação sistemática do conjunto de programas de "treinamento" ou "formação de dirigentes" nas carreiras do serviço público federal.

O que existe é uma colcha de retalhos de exercícios de treinamento, com cada departamento ou órgão executando suas próprias modalidades de programas. Cada programa de treinamento é supostamente montado para, de alguma forma, melhorar a capacidade do dirigente para administrar, organizar ou executar seus projetos. Nẩo há qualquer coerência ou consistência visivel entre programas, quer no âmbito interdepartamental quer dentro de um mesmo departamento. Entrevistas feitas no Centro de Seminários de Dirigentes, em Berkeley, com funcionários incumbidos do treinamento, diretores de programas regionais de treinamento e dirigentes revelam que os cursos são programados ou "vendidos" aos órgãos governamentais na medida em que um diretor de treinamento sinta haver necessidade deles ou em que o "Bureau of Training" (EScritório de Treinamento) da CSC ins" trua unidades de treinamento a estabelecer um curriculo (como ocorreu quando foi instituido o PPBS ${ }^{\circ}$ ). Todo órgão dispõe de determinadas dotações para "treinamento" e geralmente as distribui a vários elementos numa base completamente subjetiva. Na verdade, não fomos capazes de planejar,

\footnotetext{
- PPBS - "Planning. Programming and Budgeting System" (Sistema de Planejamento, Programação e Orçamentaçăo). (NT)
} 
desenvolver e supervisionar programas governamentais de formação e treinamento.

Em um artigo escrito em 1967, Roger Jones enumerou quatro providências que achava deviam ser adotadas pela CSC e por outros órgãos governamentais.

1. Estabelecimento de um sistema permanente e eficaz de avaliação de programas de desenvolvimento de carreiras e de dotação de pessoal em cada órgão, de esforços de treinamento de cada órgāo e entre vários órgãos, e da competência especial de alguns colégios e universidades para atender a curriculos especificos para treinamento e formação de pessoal do serviço público.

2. Pronta decisão de definir e delimitar os tipos de treinamento que melhor podem ser ministrados no âmbito da administraçăo federal para atender a suas próprias necessidades e às necessidades correlatas de governos estaduais e municipais.

3. Determinação da capacidade acadêmica e disposição (do pessoal) para receber treinamento especializado e em periodo curto, em lugar de cursos mais longos de "ampliação de horizontes".

4. Desenvolvimento de uma lista básica de aptidōes de direção julgadas necessárias para que os dirigentes de carreira possam melhorar seu desempenho. 9

9. Roger W. Jones, "Development in GOvernment Manpower: A Federal Perspective". Public Administration Review, Vol. 27 (Junho de 1967).
Até esta data nenhuma medida efetiva foi tomada numa tentativa de seguir esses rumos. A CSC parece relutar em tentar qualquer avaliação significativa de programas ou então está incerta sobre o que e como avaliar. Parece haver pouca coerência com os programas adotados em niveis interdepartamentais, intradepartamentais ou individuais. Após fazer perguntas a centenas de pessoas inscritas no Programa do Centro de Seminários de Dirigentes, encontramos poucos casos em que a capacidade acadêmica era um pré-requisito para a inscrição. Conquanto alguns órgãos tenham feito esforços corajosos para definir e desenvolver uma lista de aptidões de direção necessárias a pessoal de carreira, não foram feitos quaisquer trabalhos de verificação longitudinal, de redefinição, de pesquisa, e estudos coesos e de longo alcance dos pontos relacionados. Poucos programas de "treinamento" dos órgãos do governo traduzem uma preocupação com o fato de que $80 \%$ de todos os funcionários de nivel GS $15^{*}$ para cima têm mais de 45 anos de idade, mais da metade de todos os dirigentes de carreira nos setores científicos têm mais de 55 anos de idade e, mais surpreendente ainda, 0 fato de que dentro de cinco anos mais da metade de todos os dirigentes de carreira na administração federal estarão habilitados a requerer aposentadoria ou já estarão aposentados.

O que parece desejável é um sistema coordenado, amplo e útil de formação de dirigentes, bem como um

- O serviço público federal norte-americano está estruturado em niveis "GS" (Government Service) que văo, em escala hierárquica crescente, do nilvel 1 até 18. (NT)

R. Serv. Públ., Brasilia, 108 (1): jan/abr. 1973 
sistema que identifique o tipo de organização administrativa com que devam lidar os dirigentes no serviço público.

Devemos sublinhar o termo sistema, pois é imperativo que o desenvolvimento de carreira seja encarado como um processo ao longo de uma linha contínua, a qual se estende do nivel de ingresso an de saída projetada, permitindo assim a cada indivíduo progredir em sua carreira de acordo com seu ritmo, porém com a assistência do treinamento e formação fornecidos pelo governo. Sublinhamos sistema também porque é preciso impor certa ordem na proliferação de "cursos" discretos que são proporcionados em muitos centros de treinamento. Assim, os programas regionais de treinamento, que são totalmente separados dos Centros de Seminários de Dirigentes, deveriam ser considerados como uma parte do sistema de formação instituído pelo Governo.

Em 1969, por exemplo, o governo gastou mais de 36 milhões de dólares para "treinar" pessoal. Desse total cerca de $90 \%$ foram gastos em sessões curtas (oito horas ou menos) de treinamento em matérias como: direção em geral, ADP *, administração de ADP, aptidões burocráticas, PPBS, administração de pessoal, e "sistemas de guarda". Em maio de 1967, o decreto n. ${ }^{\circ} 11.348$ determinou à CSC "aperfeiçoar seus funcionários (do serviço público federal) através do estabelecimento e funcionamento de programas de treinamento progressivos e efici-

\footnotetext{
- ADP - "Automatic Data Processing" (Pro(NT)
}

R. Serv. Públ., Brasília, 108 (1): jan/abr. 1973 entes". A CSC atualmente se refere com orgulho a seus dez centros regionais que, durante 1969 , proporcionaram "treinamento" para 53.299 funcionários públicos federais, e a seus Centros de Seminários de Dirigentes que "treinaram" mais 1.257 funcionários. ${ }^{10}$

Nesse emaranhado de cifras perdese de vista a natureza crucial de questões como: quem decide quando um funcionário necessita de "treinamento"; em que plano amplo de carreiras individuais está baseado o "treinamento"; qual a base para se determinar se um curso deve durar oito horas ou duas semanas; qual a diferença entre programas de "treinamento" e programas de "formação", etc. Estas são questōes criticas para todos os funcionários públicos e não apenas para os dirigentes. A área mais crítica, entretanto, parece ser a do grupo situado do nivel GS 12 para cima. Nos dirigimos, portanto, aos planos de "carreira" desse grupo.

O governo tem agora uma oportunidade impar para elaborar um amplo programa de instrução que pode servir eficazmente para melhorar um sistema burocrático moribundo. 11 Programas de formação de dirigentes podem ampliar os conhecimentos do especialista, injetar concepçöes novas e inovadoras na administração, revitalizar a burocracia, promover o individualismo e abrir novas opçōes para a movimentação de dirigentes entre os órgãos do governo. O novo OMB deve, quer-nos parecer, ingressar nesse terreno e de-

10. The United States Civil Service Commission (Comissăo do Serviço Público), "Interagency Training", 1969, pg. 1.

11. Warren Bennis, "The Death of Bureaucracy". Think, Vol. 32, N.0 6 (Dezembro de 1966), pg. 30 . 
sempenhar um papel útil nesse sistema de aperfeiçoamento de dirigentes.

\section{O Predominio da CSC}

Alguns passos nesse sentido foram dados com o estabelecimento dos Centros de Seminários de Dirigentes e do Instituto Federal de Dirigentes; não obstante, neles se estão verificando algumas modificações sutis. No seu periodo de incubação, eram encorajadas formulações inovadoras, todos os órgãos participantes se reuniam para decidir sobre currículos e os instrutores tinham grande liberdade para determinar o conteúdo e a metodologia especificos. Os resultados foram excelentes programas e contribuições altamente positivas dos participantes. Isso parece estar mudando agora. A Comissão do Serviço Público (CSC) atual exige que sejam incluídas em todos os cursos "Práticas Modernas de Pessoal" ("propaganda" da CSC), junto com matérias que passaram recentemente a ser exigidas tais como "jovens e veteranos, relações trabalhistas, e igualdade de emprego". Conquanto não se possa discutir as vantagens de se examinar a maioria desses assuntos em alguma parte dos programas para formação de dirigentes, existe uma certa dúvida sobre se todos devem ser estudados em cada seminário apenas porque a CSC assim o ordena. Esse tipo de diretriz está, até certo ponto, reduzindo a flexibilidade dos Centros e sua capacidade de oferecer programas de boa qualidade.

Finalmente, um problema permanente, decorrente dos atuais programas de treinamento de dirigentes da CSC, resi- de no fato de que todos os conferencistas devem ser "liberados" por Washington (pelo Escritório de investigação da (SC). Esse procedimento obviamente impede os participantes em programas de formação de conhecerem todos os pontos-de-vista e lança um ônus sobre os responsáveis por obter as informaçōes necessárias para "liberar" um conferencista que se pretenda convidar. Essa "lista negra" e o uso que dela faz a Comissão para efetivamente "levantar antecedentes" dos conferencistas é ridicula e inteiramente inadequada em uma atmosfera de formação.

Não quer isto dizer que os programas regionais e os Centros de Seminários de Dirigentes tenham deixado de fazer um bom trabalho. Nós realmente não temos como saber qual foi o impacto de seus programas. As técnicas de avaliação atualmente usadas pelos Centros de Seminários são uma forma inadequada de "aferição de felicidade" que não fornece indicação alguma de absorção de matéria ou nivel de retenção uma semana após ter sido realizado um seminário. $\mathrm{Pa}$ rece haver por parte da CSC certa relutância para modificar o método de avaliação ou para obter assessoramento de terceiros sobre como chegar mais perto de um método de avaliação que pudesse lançar novas luzes sobre modificações necessárias de programas, estilos de apresentação ou métodos novos e inovadores de programação para formação. É necessário aumentar a capacidade dessas programaçōes de serem vitais e inovadoras e de conduzirem a seminários estimulantes, bem como é preciso que as 
atividades nelas previstas sejam coordenadas e seus programas avaliados.

Em segundo lugar, os centros regionais de treinamento funcionam quase totalmente independentes dos órgãos a que servem e a comissão assessora dos Centros de Seminários de Dirigentes raramente se reúne. Os diferentes órgãos abdicaram, em grande parte, da responsabilidade de supervisionar o conteúdo dos programas dos Centros em favor da CSC. Parece que enquanto os relatórios provenientes da CSC "pareçam bons" ao pessoal e aos responsáveis por treinamento nesses órgãos, eles não intervirão. Continuando a CSC a desempenhar ambas funções, de departamento de pessoal e de especialistas em instrução, sem qualquer contribuição direta dos órgãos servidos, não se pode deixar de chegar a um domínio ainda maior pela CSC e a uma deterioração do atual programa de treinamento. Conquanto seja intima a ligação entre um órgão central de pessoal e o aperfeiçoamento de funcionários no nivel de chefia, os programas de formação de dirigentes devem se ocupar precipuamente de questōes e problemas de programação e de diretrizes. Parece, no caso da CSC, que uma quantidade muito grande de considerações relativas a programação e diretrizes de "pessoal" foi introduzida no âmbito da instrução. É preciso que de alguma forma se opere um deslocamento que conduza os programas de formação para uma maior ênfase em programação e diretrizes, facilitando, ao mesmo tempo, o processo de planejamento de carreira de cada individuo. Somente por essa forma parece ser possivel reduzir o espirito paroR. Serv. Públ., Brasilia, 108 (1): jan/abr. 1973 quial de cada órgão, que atualmente infesta a estrutura federal.

\section{Centros Regionais}

É especialmente necessário efetuar uma completa análise e avaliação dos centros regionais de treinamento. Muitas perguntas cercam os milhares de "cursos" proporcionados nos dez centros. Quem se inscreve neles e por que? Que plano de aperfeiçoamento é mantido para cada individuo? Quem determina o conteúdo e a metodologia dos cursos? Qual é a vantagem de se ter procedimentos muito "firmes" em vez de uma metodologia mais flexivel na condução dos cursos? 0 que lucram o participante e o governo nesses exercícios de "treinamento" de curta duração? Todas essas perguntas deveriam ser formuladas pelo setor de pesquisa e avaliação da EOP * (atualmente no $\left.O E O{ }^{\circ}\right)$ ou por alguma equipe de pesquisa não-governamental. No meio tempo, esse aspecto do Escritório de Treinamento ("Bureau of Training) deveria ser alvo de exame minucioso por parte do OMB, especialmente nos casos em que os cursos são ministrados para o escalão de "dirigentes" (GS 12 para cima). Os programas regionais em especial e todos os programas governamentais de treinamento em geral oferecem uma oportunidade impar para diminuir a resistência a asspectos como mudança da missão, diretrizes novas e inovadoras, reorganização etc. No momento é minima nos-

\footnotetext{
- EOP - "Executive Office of the President", que funciona como espécie de Gabinete Civil da Presidência. (NT)

$\therefore$ OEO - "Office of Economic Opportunity" (Escritorin de Oportunidades EcO. nomicas), (NT)
} 
sa capacidade de utilizar no Departamento (Ministério) dos Transportes engenheiros disponiveis em conseqüência de uma reunião no Departamento (Ministério) da Defesa.

Precisamos, portanto, buscar formas de empregar melhor os fundos de formação e treinamento para aumentar a mobilidade dos dirigentes no âmbito federal e para auxiliá-los a desenvolver novas linhas de carreiras dentro da administração federal.

\section{Recomendações}

Durante o periodo 1969-70 ○ autor realizou um estudo de pesquisa no Centro de Seminários de Dirigentes de Berkeley, orientado primordialmente para determinar as atitudes de dirigentes no âmbito federal. Ao longo desse estudo, pesquisamos os métodos utilizados na elaboração dos programas de treinamento do governo, o processo de seleção dos participantes, o conteúdo dos programas de treinamento e a metodologia aplicada na execução dos programas.

Após estudar o processo atual, fomos levados às seguintes observações ou recomendações:

Devido às grandes diferenças em conteúdo de programa, nivel de treinamento, nível hierárquico (GS) dos Participantes, duração das sessões de treinamento e localização geográfica dos estabelecimentos de treinamento, dever-se-ia atribuir a supervisão e a direção de programas para todos os programas de formação de dirigentes no setor governamental à nova Divisão de Formação de Dirigentes do OMB.

Destacariamos várias razões básicas para essa grande alteração:

1. Os Centros de Seminários, por exemplo, foram criados para realizar seminários de aperfeiçoamento para dirigentes de nivel médio destinados a elevar suas aptidōes de chefia, etc. O curriculo deveria ser organizado por um grupo interministerial e uma comissão interministerial deveria exercer uma supervisão permanente. Durante os seus três a cinco primeiros anos de funcionamento, essa função vital foi sendo lentamente entregue ao Escritório de Treinamento da CSC e a algumas poucas pessoas "poderosas" dentro da CSC. O curriculo tem refletido cada vez mais as opiniōes da "Comissão". Os conferencistas são selecionados ("liberados") pela Comissão antes de poderem ser incluidos no programa $\dot{e}$, em numerosas ocasiōes, funcionários da Comissão foram convidados a pronunciar palestras contra a vontade do diretor do programa em questão. Todas essas atividades indicam a necessidade de colocar a supervisão desses programas de formação em um contexto de administração dentro do OMB.

2. Dada a natureza interministerial desses programas, eles deveriam ser executados com a plena cooperação e participação de cada órgão interessado. O OMB parece 
ser o único "coordenador" lógico para essa tarefa.

3. Uma supervisão abrangendo todo o setor governamental de todos os programas de aperfeiçoamento de pessoal é absolutamente essencial para se chegar a um sistema de instrução bem dirigido. Assim, por exemplo, um dos aspectos mais críticos do sistema atual, bem como do sistema futuro, é o processo de seleção de todos os participantes. Atualmente não há um processo de seleção sistemático, montado de forma a examinar os projetos de carreira de cada indivíduo, o nivel de conhecimentos de cada participante, a avaliação que cada indivíduo faz de si mesmo e o efeito dos programas de treinamento sobre os funcionários. Alguns desses temas poderiam e deveriam ser examinados imediatamente pelo novo OMB.

Uma outra razão para que o OMB fosse incumbido da supervisão dos programas de formaçăo de dirigentes reside na eliminação de uma possível orientação com finalidade de "pessoal" dada a todos os seminários, assegurando aos contros de formação o máximo de flexibilidade na organização e realizaçăo de seminários de acordo com as necessidades manifestadas pelos funcionários. Além disso, tal medida poderia resultar num maior apoio financeiro por parte do órgão em que as decisões orçamentárias poderiam ser vinculadas às necessidades de aperfeiçoamento de carreiras.

R. Serv. Públ., Brasilia, 108 (1): jan/abr. 1973
Esse raciocínio deveria servir de base para se cogitar seriamente de transferir as atividades de supervisão para o OMB. Uma segunda recomendaçăo seria a de se iniciar imediatamente um estudo de todos os programas de treinamento existentes, seus currículos, órgãos atendidos, nivel dos funcionários treinados, processo de seleção, tipos de instrutores (funcionários ou contratados), etc.

Ninguém no serviço público federal parece saber o que está ocorrendo na formação e no treinamento. Trata-se de uma vasta série, descoordenada e năocatalogada, de conferências, seminários, reuniões, sessões de treinamento e, para usar de franqueza, de atividades "para constar". Aqueles que desejam inscrever-se num programa de treinamento poderão ser selecionados se ele for realizado em Flagstaff, Arizona, ou em Augusta, Georgia, mas somente aqueles que " $\mathrm{CO}$ nhecem as pessoas certas" ou podem ser "dispensados pela organização", conseguirão ir se o programa tiver lugar em Honolulu ou Miami Beach. Embora seja dificil documentar essa declaração, este autor debateu as táticas empregadas por diversos dirigentes da administração federal para conseguirem participar de programas no Centro de Berkeley (designaçăo altamente atraente, com duração de dúas semanas e a uma distância de apenas alguns minutos de São Francisco). Foi igualmente interessante observar que cerca de um terço de todos os participantes em programas nos Centros de Seminários de Dirigentes durante o período 1969-70 não foi sequer consultado sobre se queria participar de um se- 
minário no Centro, simplesmente recebeu ordem para comparecer.

Uma terceira recomendação é a de que, como parte do atual Sistema de Designação de Dirigentes (que até hoje tem sido bastante inútil), dever-se-ia colher informações sobre tendências para desenvolvimento de carreiras e desejos de cada pessoa, bem como se deveria incluir planejamento de longo prazo nos sistemas de informação. Isso permitiria ao novo Escritório de Aperfeiçoamento de Dirigentes do OMB determinar, através de computadores: pessoas que desejam receber treinamento, tipos de programas de treinamento existentes, deslocamento de funcionários nas carreiras, localização das pessoas que desejam treinamento em relação aos locais de treinamento, etc. Dessa forma não se preveria a manutenção da concepção atual do Sistema de Designação de Dirigentes (EAS). É pura fantasia presumir que se possa, através dos meios do EAS, chegar a decisões ou mesmo recomendações aceitáveis em matéria de Pessoal. Embora esse processo possa ser desejável e talvez pudesse até ser melhor executado por meio de computador, parecemos estar muito longe de aceitar tal posição. É essencial que so proceda a mais estudos o experiências de deslocamento de dirigentes entre órgãos do governo e a OMB os deveria fazer, especialmente à luz do novo "Instituto para Administraçăo de Pessoal" (IPA). Nossos comentários anteriores sobre o individuo no serviço Público federal assumem relevância esPecial neste contexto. Um indivíduo deve sentir-se livre para se deslocar entre órgãos do governo, ser capaz de discernir possibilidades de aperfeiçoamento e, então, ser capaz de planejar sua carreira no serviço público. Tal situação ofereceria um grande contraste com as condições atuais, em que o funcionário público. é "punido" por mudar de um para outro órgão, pois isso - faz perder tempo de classe em um órgão ou o faz parecer insatisfeito e instável.

Da mesma forma, tanto a sociedade como o indivíduo lucram com a livre movimentação de pessoas de uma para outra organização. Nossa própria sociedade dá a impressão de completa fluidez, mas isso é parcialmente ilusório. Há relativamente pouca movimentação, por exemplo, entre os setores governamental, industrial e acadêmico a despeito de alguns casos espetaculares de elementos que cruzam essas fronteiras. $\mathrm{E}$ a mobilidade entre organizações está sendo reduzida por planos de aposentadoria nos quais os benefícios dependem da permanência do indivíduo na mesma organização. 12

Atualmente o indivíduo tem pouco ou nada a dizer sobre seu programa de instrução dentro do serviço público; este é determinado por funcionários e administradores de treinamento e de pessoal. Tal circunstância obviamente deixa a carreira do indiviđuo à mercê dos que estão acima dele, a menos que seja uma pessoa excepcionalmente decidida e ambiciosa que consiga conhecer as "pessoas certas" nos "lugares certos" e que siga as

12. Garner, op cit., pg. 77.

R. Serv. Públ., Brasilia, 108 (1): jan/abr. 1973 
normas "certas" nos momentos "certos".

Uma observação final é a de que se deve criar um "centro de seminários" ou, talvez mais apropriadamente, um "instituto de aperfeiçoamento de dirigentes governamentais" em cada uma das dez regiōes. Esses centros deveriam funcionar como instituiçōes oficiais de ensino, dirigidas por um órgão misto (oficial-particular) em cada região, com uma junta consultiva composta de representantes federais, representantes estaduais e municipais e representação particular (talvez de universidades ou empresas). Essas juntas poderiam assessorar a divisão executiva do OMB e do Conselho Regional de cada região. O OMB deveria então exercer a supervisão geral dos programas globais. Esses centros poderiam ser estruturados segundo os atuais centros de seminários, localizados dentro ou nas proximidades de campi universitários, oferecer cursos que outorgassem créditos reconhecidos em faculdades, manter intimas relaçōes de trabalho com universidades e fornecer um programa vital de aperfeiçoamento de dirigentes a todos os ramos do governo.

Um recente artigo de John Rehfuss publicado no "Public Administration Review" (PAR) 13 sustenta que os programa governamentais de treinamento

13. John Rehfuss, "Executive Development: Executive Seminar Style". Public Administration Review, Vol 30 , N.o 5 (Setembro não levam em conta possiveis modificações futuras na estrutura organizacional. Concordamos totalmente com essa observação e com o ponto-de-vista de que com essas modificações devem vir novos métodos de treinamento. maiores oportunidades de treinamento, programas mais individualizados, etc.

A forma e o estilo das organizaçōes futuras serão determinados pelos indivíduos que ocupam os postos de direção dentro dessas organizações. Somente contando com liderança imaginativa e inovadora podemos esperar algum desafio a um sistema burocrático que deixa muito a desejar. A formação de dirigentes governamentais inovadores, que "pensem por conta própria", que não estejam constantemente dominados pelo medo de "virar o barco" é o grande desafio atual aos administradores públicos. O dirigente do futuro deve ser capaz e ter disposição de desafiar velhos métodos, velhos regulamentos e teorias que náo têm mais utilidade. Para que as organizações se modifiquem, para que as instituições sobrevivam, é preciso que os individuos, e especialmente os dirigentes, adquiram consciência das mudanças que são necessárias em atitutudes pessoais, niveis de conscientização, processos de comunicação, problemas sociais, etc. Este é o desafio dirigido ao Escritório de Administração e Orçamento (OMB), à Comiśsão do Serviço Público (CSC), aos dirigentes do serviço público e a cada órgão ao despender suas verbas para "treinamento". 